\title{
MAESTRAS QUE ESCRIBEN LIBROS PARA SUS ALUMNOS. ARGENTINA, PRINCIPIOS DEL SIGLO XX
}

\author{
Primary School Teachers who wrote Textbooks for their Students. \\ Argentina, early XX Century
}

\begin{abstract}
AGUSTINA GUADALUPE MOSSO*1
https://orcid.org/0000-0003-3515-7641

* Investigaciones Socio Históricas Regionales - Consejo Nacional

de Investigaciones Científicas y Tecnológicas (ISHIR-CONICET),

Argentina.agustina_mosso@hotmail.com
\end{abstract}

Recibido: 20-02-2018

Revisado: 15-07-2018

Aceptado: 05-05-2019

Resumen: El presente artículo reúne los primeros avances de una pesquisa en torno a maestras que, además de ejercer en el aula, escribieron libros de texto para sus alumnos durante la primera mitad del siglo XX en Argentina. Se encontraron numerosas pruebas que permiten pensar que las maestras, como agentes alfabetizados, complejizaron las prácticas de enseñanza en el aula escribiendo para sus alumnos distintos materiales, como manuales, libros de lectura o cartillas para alfabetizar. En este artículo, se trabaja con los libros de texto a modo de territorios de imposición simbólica e institucionalización de las relaciones entre saber y poder en la escuela (Martínez Bontafé citado en Sardi, 2010, p. 91). Primeramente, se estudian las notas características del sistema educativo argentino del período -en el que estas mujeres ejercieron la docencia y para el cual produjeron sus escritos-, que resultan fundamentales para comprender el posterior análisis de los libros de texto.

Palabras clave: magisterio; libros de texto; Argentina; imposición simbólica.

\begin{abstract}
This article brings together the first advances of a line of research that investigates primary teachers who, in addition to exercising in the classroom, wrote textbooks for their students during the first half of the twentieth century in Argentina. Numerous evidences were found that suggest that teachers, as literate agents, brought complexity to the classroom with teaching practices by writing materials for their students, among which we can mention manuals, reading books or literacy cards. In this article, textbooks are used as territories of symbolic imposition and institutionalization of relations between knowledge and power in the school (Martínez Bontafé as cited in Sardi, 2010, p. 91). First, the characteristic notes of the Argentine educational system of the period - in which these women taught and for which they produced their writings - are studied, since they are fundamental for understanding the subsequent analysis of textbooks.
\end{abstract}

Keywords: primary school; textbooks; Argentina; simbolic imposition.

\footnotetext{
1 Profesora (2014) y licenciada (2016) en Ciencias de la Educación. Facultad de Humanidades y Artes, Universidad Nacional de Rosario (Argentina). Doctoranda (con beca CONICET desde 2017) en el Doctorado en Estudios de Género de la Universidad de Buenos Aires. Línea de trabajo: género y educación.
} 


\section{INTRODUCCIÓN. ENCUADRE HISTÓRICO}

Si nos ubicamos en la segunda mitad del siglo XIX, encontramos a una Argentina conmovida por discusiones sobre formación de docentes. Fue allí donde aparecieron opiniones acerca de si era conveniente incorporar o no a las mujeres al ejercicio del magisterio. El siglo XX definitivamente las colocó frente a los trabajos relacionados con la tarea de enseñar, pero de un modo particular: se convertirían en segundas madres, protectoras ya no solo del hogar, sino también de la escuela. Sabido es que con la Ley de Educación Común N. 1420, sancionada el 8 de julio de $1884^{2}$, encontramos los frutos del accionar sarmientino (Solari, 1991, p. 187), pero a su vez, y con los principios fundamentales de la norma —obligatoriedad, gratuidad, gradualidad, laicidad-, entendemos que aparece la base para la organización de la escuela primaria argentina.

En ese momento prevalecían consideraciones materiales que, junto a la percepción de que las mujeres estaban mejor preparadas para encarar la educación primaria, determinaron que el Estado debiera diseñar políticas con el afán de feminizar el magisterio (Fiorucci, 2016, p. 122). Se propaga entonces, y junto a la ley, un discurso sobre la importancia de la madre educadora profesional, que llega a Argentina en el siglo XIX desde Europa y es adaptado a los intereses locales de países recientemente independizados (Yannoulas, 1996).

El Estado nacional, garante del derecho, necesitaba quién ejerciese la profesión docente para expandir la educación popular asegurando nuevas instituciones políticas, a la vez que constituyendo la base para la homogeneización cultural. Sin profesionales que llevaran a cabo esta tarea, se la confía a las mujeres, quienes ingresan al mercado de trabajo y comienzan a vivir -más allá de condiciones laborales no tan agraciadas como las de los hombres - fenómenos emancipadores como el acceso a más y mejores conocimientos, la circulación libre en espacios públicos, la obtención de un dinero con el cual adquirir posiciones propias y el acceso a la escritura de libros. Será esto último lo que en adelante guíe nuestra pesquisa.

No se puede negar la flagrante contradicción que suponía hacer a las mujeres responsables de crear al ciudadano mientras que estas eran privadas del derecho a una ciudadanía plena (Fiorucci, 2016, p. 123). Había en ese entonces un conjunto de ideas que pretendían demarcar el lugar de la mujer en la sociedad, mientras el magisterio estaba, sin dudas, a cargo de las mujeres.

Como se mencionó, en 1884 el Congreso de la Nación debatió y aprobó la Ley N. 1420, cuya jurisdicción abarcaría la Capital Federal y los territorios nacionales. Con esta ley se estableció un Consejo Escolar en cada distrito de la campaña y un Consejo Nacional de Educación (Puiggrós, 1996, p. 64). Fue este Consejo el órgano gubernativo que sancionó, en 1877, el Reglamento sobre textos escolares, destinado a marcar las pautas esenciales para que las comisiones reunidas al efecto (Alloatti, 2007, p. 95)

\footnotetext{
${ }^{2}$ Durante la primera presidencia de Julio A. Roca.
} 
aprobaran o no los libros de lectura que autores y directores presentaban bajo solicitud. Quedó entonces a cargo del Estado nacional la introducción del sistema escolar primario en todo el país, a la par que cumplía con la edición y reedición anual de los libros de texto que subscribía su Consejo, con la finalidad de difundir el aprendizaje de la lectura a todo el público infantil.

Creyendo que en la aplicación idónea del método se jugaba el éxito de la empresa alfabetizadora (De Miguel citado en Alloatti, 2007, p. 98), la Ley N. 1420 en su capítulo IV (Inspección técnica y administración de las escuelas), en el artículo 36, dice: "Corresponde a los inspectores de escuelas primarias: $3^{\circ}$ comprobar la fiel adopción de textos, formularios y sistemas de registros, estadística e inventarios establecidos por la autoridad superior de las escuelas" (Congreso de la Nación Argentina, 1884).

Asimismo, en el capítulo VI (Dirección y administración de las escuelas públicas), en su artículo 57, se establecen como atribuciones y deberes del Consejo Nacional de Educación: "15. Prescribir y adoptar los libros de texto más adecuados para las escuelas públicas, favoreciendo su edición y mejora por medio de concursos u otros estímulos, y asegurando su adopción uniforme y permanente a precios módicos, por un término no menor de dos años" (p. 26) y “19. Dirigir una publicación mensual de educación” (p. 27). Esta publicación mensual es El Monitor de la Educación Común, revista oficial que había empezado a propagar sus escritos en 1881.

Sin embargo, y desde un poco antes de la conformación plena del Estado federal argentino, la atención de la instrucción escolar había generado la publicación de un nuevo objeto cultural: el libro de lectura, objeto de estudio del presente artículo. Este fue un fenómeno presente con mayor intensidad en las escuelas de la provincia de Buenos Aires (Alloatti, 2007, p. 94) y los organismos encargados de dar a conocer las publicaciones, materializadas además con imágenes muy diversas, fueron los siguientes: Talleres Gráficos Cappellano Hermanos, Editorial A. Kapelusz \& Cía., F. Crespillo Editor, Editorial Independencia y Ángel Estrada y Cía. Editores.

En el artículo 6 del capítulo I de la Ley N.․ 1420 se estipuló como la enseñanza destinada a niñas y niños aquella que comprendía, entre otras materias: lectura y escritura, aritmética, geografía, historia, idioma nacional, moral y urbanidad, nociones de higiene, ciencias matemáticas, físicas y naturales. Para las niñas era obligatorio el conocimiento de labores de manos (tejido, costura, manualidades) y nociones de economía doméstica. Para los varones, el conocimiento de ejercicios y evoluciones militares, por ejemplo. Además de este mínimo de instrucción obligatoria, y dentro del articulado de la ley, aparecen otras regulaciones: delimitación de edad de sujetos a quienes iba dirigida la educación, la caracterización de esta como gradual (con divisiones al interior) y los tipos de escuelas que ofrecían dicha instrucción (Infantiles, Elementales, Superiores), que podían encontrarse bajo un mismo establecimiento o separados. Estas definiciones se manifestaron en escuelas nacionales y provinciales, hasta tanto las jurisdicciones fueron a su vez sancionando leyes de educación en concordancia con la

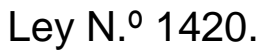


En los primeros treinta años del siglo XX se reconoce un discurso patriótico predominante, a cargo de una intelectualidad letrada que hace derramar de arriba hacia abajo una cultura desarrollada que implica un idioma nacional y ciertas prácticas culturales a través del sistema educativo. El fervor nacionalista deviene de un discurso que se expande por todas las esferas sociales y su herramienta privilegiada para la transformación cultural y la imposición del universo simbólico oficial es la escuela. Esta se puebla de prácticas, discursos, rituales, liturgias y racionalidades que funcionan como instrumentos para combatir la diversidad lingüística y cultural que trae el cosmopolitismo (Sardi, 2010, p. 26). Localizamos en el concepto de educación común los grados, áreas disciplinares, planes de estudio, programas y horarios para todas las escuelas públicas dependientes del Consejo Nacional de Educación.

Ahora bien, en los concursos realizados bajo intervención de dicho Consejo se determinaban los textos que serían utilizados en las escuelas; se convocaba allí a autores, editores, introductores de libros a presentar sus solicitudes acompañadas de los ejemplares. Desde entonces podía pensarse al libro de lectura escolar como instrumento organizador de la práctica escolar, que legitima los saberes que lo conforman y pauta el currículum activo, a la vez que regla los modos de pensarse como alumno y como sujeto de una comunidad de pertenencia. Dicho libro debía normalizar la población escolar que ingresaba a la escuela en el período considerado y que llevaba el lastre de lo heteróclito y contaminante (Sardi, 2010, p. 91).

Los escenarios privilegiados para postular las distintas concepciones sobre el libro de lectura, su uso y efecto en la escuela fueron los informes ministeriales, los digestos, las revistas pedagógicas - oficiales y contrahegemónicas-y los prólogos de los propios libros. Estos espacios funcionaron como territorios de la intervención docente, como espacios discursivos desde los cuales los maestros, profesores, pedagogos, autores de libros y funcionarios ministeriales opinaron acerca del lugar que le debía corresponder a este dispositivo escolar (Sardi, 2010, p. 67) y respondieron al mismo tiempo a los requisitos que el Consejo Nacional exigía para integrar el recinto educativo.

\section{MARCO TEÓRICO Y METODOLÓGICO}

Tomando los aportes de la historia con mujeres en perspectiva de género, junto a la historia social y de la educación bajo un registro cultural, nos disponemos a indagar sobre la producción de textos escolares realizados por las maestras. Para ello emprendimos una búsqueda por diversos archivos ubicados en la ciudad más poblada de la provincia de Santa Fe, Rosario (en la Biblioteca Argentina y la Biblioteca Pedagógica Eudoro Díaz). Con lo allí revelado se conformó un corpus de libros de texto para analizar y, con apoyo en un enfoque metodológico cualitativo, interpretativo y de lectura crítica de estos documentos escritos (Aróstegui, 1995), se realizó un compendio de la producción editorial de un grupo particular de mujeres. Partiendo de un supuesto muy propio de la 
historia sociocultural, nos interrogamos asimismo acerca de la tensión entre las prescripciones y las prácticas (Chartier, 2001).

La Ley $\mathrm{N} . \stackrel{0}{1420}$ de educación primaria pública, laica, gratuita y obligatoria establece en su misma letra un corpus de saberes con el objeto de formar varones y mujeres capaces de ocupar los lugares que la sociedad deparaba para cada uno. ${ }^{3}$ Estos contenidos fundamentaron la existencia del Estado nacional y de la educación patriótica y ciudadana, por lo cual los acontecimientos políticos con sus consecuentes próceres fueron la clave de la enseñanza. En este punto, los manuales, los contenidos áulicos y las efemérides operaron sobre una agenda cuyas connotaciones apuntalaban lo nacional. Sin embargo, nos preguntamos por la singularidad de las prácticas en toda la extensión de una geografía extendida mucho más allá del lugar físico donde estaba emplazada la toma de decisiones acerca de las prescripciones escolares. La distribución de los libros partía de la ciudad de Buenos Aires, pero se disponía a ser utilizada por el resto del país, con las particularidades y características del territorio.

Estudiar a las maestras como creadoras de saberes que culminan en producciones editoriales es una idea madurada en el marco del Proyecto de Investigación y Desarrollo "La historia en el currículum de las escuelas primarias de la provincia de Santa Fe, 1884-1930". En este contexto indagamos a Olga Cossettini, una maestra que escribió y publicó sobre sus prácticas pedagógicas. Los resultados de esta búsqueda dieron lugar a trabajos de factura personal o grupal (Caldo, Pellegrini, Mosso, 2016) y posibilitaron el desarrollo actual de una investigación determinada por el Consejo de Investigaciones Científicas y Tecnológicas (CONICET).

Con todo, y a los efectos del presente trabajo, construimos los antecedentes consultando primero investigaciones sobre la relación mujeres-escritura. Luego, sobre maestras y el proceso de feminización de la docencia y, finalmente, sobre las maestras como productoras de saberes y como intelectuales. Este trabajo nos ofreció un panorama significativo para el desarrollo de categorías conceptuales como el de lgnasi Terradas (1992), quien utilizó una forma particular de escribir y pensar los relatos de vidas a través de lo que llama antibiografías. En su mirada anidaba la pregunta por la singularidad de los contextos sociales que conducen a la invisibilidad-desaparición de ciertos sujetos 0 , incluso, grupos sociales (Caldo, 2017, p. 28).

Poder pensar en la sociedad occidental del período, que omitió el advenimiento de las maestras como autoras de libros, nos conduce a buscar en aquellos momentos en los que el hacer escapa al orden del discurso, así como también donde los actos son puestos en palabras (Chartier, 2001). Resulta indispensable, entonces, desandar sobre los intereses que llevan a estas maestras a escribir acerca del conjunto de acciones que

${ }^{3}$ Varones que trabajan, estudian, gobiernan y transitan por el espacio público junto a mujeres que son su complemento y, en ese rol, asumen los cuidados del hogar, la maternidad, las prácticas de beneficencia y sociabilidad públicas y demás actividades vinculadas al cuidado de los otros (maestras, enfermeras). Ver Lucía Lionetti (2007) o Carolina Kaufmann (2012). 
desarrollaron en las aulas, si nos proponemos no confundir decir con hacer e historiamos las condiciones sociales que impulsan la necesidad de crear discursos con las prácticas (Caldo, 2017, p. 50), como así también pensar en la escuela como espacio donde las mujeres podían potencialmente desafiar la jerarquía de géneros prevaleciente en la sociedad. El ejercicio de la docencia las proyectaba a un lugar de relevancia social (Fiorucci, 2016, p. 135); veremos, a continuación, si así sucedió también en las que se animaron a desarrollar prácticas de escritura.

En concreto, en este artículo se analizan libros de texto escolares escritos por maestras que intentaban señalar, a docentes y alumnos, nociones generales sobre la enseñanza de los temas estipulados para los diversos niveles del sistema educativo, en la educación primaria. Se estudiarán dos libros de lectura para el primer grado superior de la enseñanza primaria _Por nuestro bien, de Micaela lantorno de Nasino (1926), y Días de sol, de Evangelina Malvigne de Mercado Vera (1930)_; un texto de lectura para primer grado, Sol, de Alcira del Prado (1932), y dos libros cuyos destinatarios eran alumnos del cuarto grado de la enseñanza primaria: El hogar de todos, de Clara de Toro y Gómez (1936) y Lucha, firmado María Olguín y Virginia Zamora Grondona (1936).

Fijaremos la mirada en los prólogos e índices de los libros para intentar describir, en líneas generales, las estrategias utilizadas por estas maestras para publicar sus escritos (bajo cumplimiento de normas establecidas por el Consejo Nacional de Educación) y el contenido que ellos exhiben; las diferencias y similitudes que entre estos se vislumbran; el tono que sus autoras les otorgan al momento de escribirlos —cuando remiten a los docentes como colegas receptores principales de sus obras, a los alumnos a quienes el detalle sobre las actividades va dirigido, los motivos por los cuales se disponen a escribir sobre prácticas educativas - y los objetivos o presunciones que trazan para llevar adelante sus producciones.

En el cuerpo de este artículo cristalizan, a continuación, dos apartados. El primero, de carácter general, analiza el contenido de los cinco libros seleccionados con los criterios arriba mencionados. Luego, en un segundo apartado, se puntualizan algunas conclusiones primarias que abren nuevas posibilidades de análisis sobre la temática.

\section{MAESTRAS Y ESCRITURA: QUÉ HAY DENTRO DE LOS LIBROS DE SU AUTORÍA}

Los libros seleccionados dan a conocer la intervención y el reconocimiento público que quienes los escribieron obtuvieron como resultado de gozar de un título, el de maestra normal nacional, que certificaba su saber y destreza en las prácticas de lecto-escritura. Gracias a tal designación, estas educadoras pudieron desempeñarse no solo como escritoras, sino también como autoras de libros, autorizadas a divulgar los escritos bajo la aprobación del Consejo y mediante su publicación editorial. Sin embargo, no asumieron las destrezas propias del oficio intelectual: sus obras se centraron en la tarea educativa y giraron en torno a dicha actividad, solo pudiendo trascender gracias al reconocimiento obtenido en las escuelas. 


\section{Por nuestro bien, de Micaela lantorno de Nasino}

El primero de los libros fue escrito por Micaela lantorno de Nasino en 1926. Al igual que los demás escritos aquí estudiados, tiene la aprobación del Consejo Nacional de Educación. Editado por Talleres Gráficos Cappellano Hermanos, de la ciudad de Buenos Aires, el prólogo está firmado por la autora y fechado en el mes de setiembre del mismo año de publicación de la obra.

La maestra dice allí que su intención no fue presentar "un libro más" y que su texto quizás no sea "obra nueva, pero sí obra útil" (lantorno de Nasino, 1926, p. 3) para lograr que el niño salve con mayor facilidad las dificultades que pueden presentársele en el aprendizaje de la lecto-escritura. Su característica principal, entonces, es ser beneficioso para los procesos educativos. En el mismo prólogo, la autora refiere a la aprobación de "los señores miembros de la Comisión de Textos del Consejo Nacional de Educación" con motivo de revalidar su libro y resignificar un trabajo que define como "de rigurosa coordinación metódica" (p. 3). Por este motivo, la maestra aguarda que tanto directivos como maestros lo utilicen como texto de lectura para primer grado superior.

El índice de Por nuestro bien se encuentra dividido en cuatro partes, que a su vez se dividen en secciones. En la primera sección de la primera parte (p. 5) aparecen temáticas como "El barrilete", "El niño estudioso", "Un soldadito", "El aseo es el mejor adorno", "Trabajar es un deber". La segunda sección (p. 15) comienza con "Flores y frutas" (y se aclara que es para ser usado como tema de conversación) y algunos de los textos que la integran son "No debes ser glotón", "Muertos por la patria", "El perrito travieso" y "Piedras preciosas". En la tercera sección (p. 25) figuran "Deseos de aprender", "Las dos muñecas", "Al aire libre", "El gatito herido", "El cumpleaños del abuelo", "Algo de historia" y "La lección de mamá". En la última sección (p. 39) se lee: "Leve accidente", "A cazar", "Lo que vio Elsita", "Narraciones del abuelo", "Poetas argentinos", "Una mala acción" y "Mirando sus juguetes".

En la segunda parte (p. 55), la primera sección contiene "Una imprudencia evitada", "Oro y cobre", "Primer gobierno patrio" (tema de conversación), "Una pequeña lectora", entre otros. La segunda sección (p. 66) posee los títulos: "No se debe mentir", "El progreso en los medios de transporte" (tema de conversación), "La limpieza en todo". La tercera (p. 74) dicta "El globo geográfico", "La imprudencia no es valor", "Ayudemos a los necesitados" y "Uno de nuestros héroes", mientras que la última sección (p. 83) contiene "La zeta no es comestible", "Sembrando trigo" (tema de conversación), "Pequeño pero listo".

La tercera parte nos muestra en la sección inicial (p. 92) los textos "Cielo nublado" y "Papel mata mosca". La segunda sección (p. 96) comienza con "Madre", un texto al que le siguen "Desobediencia castigada", "Declaración de la Independencia argentina" (tema de conversación), "Fechas gloriosas" y "Mi bandera". La penúltima sección (p. 108), "Sombra y frutas", "Domingo Faustino Sarmiento", "Los puntos cardinales" y "Las 
estaciones", y la última inicia con los temas de conversación "El gaucho" y "Diarios y cartas", seguidos de "Cayó pero no calló", "Podemos osar, pero no hozar".

Finalmente, en la cuarta y última parte (p. 115), hay tres secciones: la primera tiene, entre otros, los textos "El respeto a los ancianos", "El alcoholista" (tema de conversación), "El atlas del abuelo", "Aire, limpieza y luz"; la segunda, "Volvieron las golondrinas", "El ombú", "Nuestro himno nacional"; y la tercera, "En lo alto o en lo profundo", "La hija del vigía", "La escuela" y "Yo sé leer", entre otros asuntos más.

Cada página de Por nuestro bien incluye notas al pie que sirven al alumno para comprender aquellas palabras que quizás desconoce. Es probable que lantorno de Nasino haya decidido colocarlas a modo de sugerencia, dejando a los docentes agregar o quitar las que creyeran necesarias. Este libro, además, posee una serie de poemas. Es posible intuir que es la propia autora quien los escribe, porque no presentan una firma al final. En ellos abundan los diálogos en los que aparecen, entre otras cosas, consejos para los niños sobre el buen obrar.

\section{Lucha, de María Olguín y Virginia Zamora Grondona}

Este libro está destinado al cuarto grado y fue aprobado por el Consejo bajo el expediente número 15136-E-1927. Para el presente análisis contamos con la décima edición ${ }^{4}$ de la obra, que fue publicada en 1936 por Ángel Estrada y Cía. Editores, en la ciudad de Buenos Aires. En el prólogo de la primera edición, fechado en enero de 1926, las autoras dejaban en claro que su obra pretendían auxiliar a las demás materias que formaban parte del programa de enseñanza. El libro de lectura era, entonces, una ayuda para las necesidades intelectuales de los alumnos, y su producción estaba a cargo de mujeres que llevaban años en la práctica de la instrucción primaria y que no dejan de pensar en el trabajo diario de sus colegas. Se trata entonces de otro libro que se caracteriza por ser útil a docentes y alumnos.

Olguín y Zamora Grondona (1936) exponen en Lucha un sinnúmero de temas concernientes a todas las asignaturas del programa oficial, pero de un modo innovador. Los contenidos están organizados por meses y no por materias. Suponemos que las autoras intuyeron que ordenar los asuntos de este modo facilitaría a maestros y alumnos su aplicación. El libro presenta una entretenida lectura sobre diversidad de temas que debe trabajar un alumno de cuarto grado: moral, higiene, educación cívica, naturaleza (las estaciones del año que transcurren estando el niño en la escuela), historia, trabajos literarios (prosas y poesías de autores reconocidos), geografía, botánica, zoología, mineralogía, fenómenos físicos y químicos, etcétera.

Al momento de escribir su libro, estas maestras fueron muy organizadas y aclararon en él todos los detalles, sin dejar ningún aspecto librado al azar. Entre paréntesis mostraban la correspondencia entre el título y la materia que ellas

\footnotetext{
${ }^{4} \mathrm{El}$ hecho de que haya tenido tantas ediciones permite intuir el éxito que tuvo esta obra.
} 
consideraban debía incluir esa temática. Por ejemplo, si nos centramos en el mes de marzo ubicamos: "Las clases se inician”, "Árboles viejos” (poesía), "Evocando”, "Nueva vida", "Guillermo Brown" (historia), "Un pueblo subterráneo" (zoología), "Seamos curiosos" (botánica), "No creamos en las alabanzas" (moral), "Muerte de Florencio Varela" (historia), "La canción de las hojas" (otoño), "Paz es riqueza" (poesía), "Los experimentos de Guillermito" (fenómenos químicos), "Una fuente de riqueza".

Ya por el mes de julio leemos: "La conquista del aire", "Ignacio Pirovano", "9 de julio" (poesía), "Casas y cosas de otros tiempos" (historia), "Los cabellos de la abuelita", "Fuentes minerales y termales" (mineralogía), "Por qué llegó tarde Marcelito" (instrucción cívica), "Ahorra". En el capítulo correspondiente a octubre aparecen los textos "2 de octubre" (día de los niños pobres), "El camino de Uspallata" (geografía), "Patrón rico, fábula" (moral), "Últimas palabras de un moribundo" (zoología), "Día de la raza", "El sol dentro de una caja" (fenómenos químicos), "Una tormenta" (lenguaje), "Una dama patricia" (historia), "Carta descriptiva" (geografía), "Plegaria por el nido” (poesía), "Un espectáculo vergonzoso" (higiene - semana de la templanza), "La madrecita" (higiene día del hermanito), "Comodoro Rivadavia" (geografía) y "Día de los servidores de la Patria". En el último capítulo, correspondiente a noviembre, encontramos: "La vacuna" (higiene), "Un crepúsculo en Misiones" (lenguaje), "Recompensa inesperada”, "El ombú”, "El resultado de este año" y el "Himno al maestro".

La obra contiene fragmentos de poemas de autores como José Santos Chocano, José Zorrilla de San Martín, Eduardo Wilde, Rafael Obligado, Godofredo Daireauz y Gabriela Mistral, única mujer citada. También se leen cuentos con moralejas y referentes a temáticas como la madre. El libro contiene exposiciones sobre hechos de carácter complejo, que combinan análisis con relatos extensos y diversos. Aparecen diálogos entre personas (padre-hijo, hermanos, explicaciones de una abuela) y objetos (monólogo de la aguja, de una veleta, lo que nos contó una estrella) donde los interlocutores se educan. Vemos, por ejemplo, cómo un niño aprende nuevas cosas a partir de la lectura de los cuadernos de su padre. La escuela es lugar recurrente de muchos de los relatos; y aparecen además nombres de calles o datos específicos de lugares con sus correspondientes observaciones (Comodoro Rivadavia, Uspallata, Misiones).

Advertimos la aparición reiterada de la temática que aborda la relación entre el hombre y la naturaleza bajo los aspectos del cuidado, por ejemplo, de la flora y la fauna autóctonas o la comparación entre los hábitos humanos y los de otros seres vivos para que la humanidad aprenda de las buenas prácticas de animales y plantas. También figuran recetas medicinales con flores cultivadas y silvestres.

$\mathrm{Y}$, finalmente, aparece en el libro el infaltable catálogo de valores, para que los más chicos los pongan en práctica (son ellos, a veces, quienes enseñan a maestros y compañeros). 


\section{Días de sol, de Evangelina Malvigne de Mercado Vera}

El de Malvigne de Mercado Vera (1930) es un texto de lectura destinado al primer grado superior de la enseñanza primaria. El tomo analizado aquí pertenece a la tercera edición, publicada en Buenos Aires por F. Crespillo Editor. Al inicio del libro, en el apartado "A mis colegas", la autora no señala ni su firma ni el año en que escribe. ${ }^{5}$ Bajo dicho título, la autora incluye el epígrafe "Se aprende a leer, leyendo" (p. 7). Valiéndose de esta cita, aclara que su obra es para enseñar a los alumnos y ayudar a los maestros.

El compendio viene a cerrar varios años de trayectoria de la maestra en el primer grado superior, años que le han sido de utilidad para, mediante la observación detenida de los comportamientos de los niños en las aulas, confeccionar un libro que los ayude a aprender a leer de corrido, amar la lectura, saber interpretar los escritos e interesarse por estos. La maestra se dirige a sus colegas para explicarles, entre otras cosas, las particularidades que considera fundamentales en los chicos y para aclarar cuestiones referentes a la redacción del libro. Además, les promete resolver algunos de los problemas que suelen aparecer en las clases.

Malvigne de Mercado Vera ofrece, con un estilo propio, un matiz especial en los asuntos referentes a las materias y contenidos que se adecúan a los requerimientos de la edad de los niños, respondiendo siempre al programa oficial del grado. Para describir el contenido resulta útil ir al final del libro, donde aparece un rótulo denominado "Guía". En ella figura, en primer lugar, el detalle de las lecturas que a lo largo del libro se refieren a distintas efemérides; luego la guía se divide por materias y detalla "temas de conversación, composición o composiciones modelos" de cada una: lenguaje, historia, geografía e instrucción moral y cívica, aritmética y geometría. Luego aparece un título que figura como apartado general, denominado "Naturales", que incluye cuerpo humano e higiene, animales, plantas, minerales, fenómenos físicos y meteorológicos, cielo y astros.

A continuación de esta guía, aparece el índice que detalla los escritos del libro ordenados por página y que se divide en dos partes. La primera, sin título previo, va hasta la página 54 y contiene títulos como "Mi bandera", "Los pajaritos", "Un volcán", "La medalla de plata", "Seamos aseados", "Mañanita de invierno", "Goloso", "Primavera", "Un consejo", "Obsequios de navidad", "Día patrio", "Trabajadores honestos", "Clase de dictado" y "Estío". Luego aparece el título "Segundo término", bajo el que aparecen textos como "Por vuestra salud", "Números romanos", "Ahorro", "Hombres ilustres", "El gusano de seda (cuento real)", "Los animales en libertad", "Los indios", "En el acto de fin de año" y "Mi escuelita (zamba)".

El libro presenta un formato que respeta, a lo largo de toda su lectura, la aparición de sílabas, títulos, el cuerpo del texto al que refiere dicha inscripción e imágenes. Son

${ }^{5}$ Intuimos que este texto fue redactado algunos años antes de 1930, fecha de la tercera edición del libro. 
reiterados los diálogos entre madres y padres con sus hijos, en los cuales se habla sobre la familia (se presenta la figura de los primos, por ejemplo), la higiene, los animales (la vaca y los alimentos, la cocina), el trabajo. También hay cuentos relatados por la maestra, en los que los niños enseñan y aprenden juntos o donde ellos mismos recitan poemas sobre las estaciones o los símbolos patrios. Hay también una exhaustiva enumeración de proverbios, así como profusas menciones a temas referentes al conocimiento, estudio y cuidado de la naturaleza, los animales y las plantas. Finalmente, se destaca el tratamiento que se efectúa sobre el calendario litúrgico en el que aparecen, entre algunas de las fechas más representativas, la celebración de la Navidad.

\section{Sol, de Alcira del Prado}

Alcira Del Prado (1932), en su libro para primer grado, se luce con un escrito que propone un método novedoso para enseñar a leer y a escribir. Del mismo modo que las maestras anteriores, su experiencia en las aulas la anima a dar a conocer este libro que coloca en concursos y obtiene diversas aprobaciones: la del Consejo General de Educación de la provincia de Buenos Aires y la del Consejo Nacional de Educación, así como también las del Consejo General de Educación de las provincias de Santa Fe, Santiago del Estero, Mendoza y San Juan. Aquí se analiza una cuarta edición, perteneciente a la editorial porteña Independencia.

"A los maestros" se titula el primer apartado, en el que la autora explica cómo surge el término "sol" como clave metodológica de la obra. Del Prado invita a sus colegas (conocedores de las eventualidades del magisterio, dice) a poner en práctica los ejercicios que propone. Cierra este apartado reafirmando los aportes que espera consumar con la publicación de su libro, entre los que destaca "la sinceridad de nuestro propósito, con el que colmamos, de paso, aquel anhelo de todos los que enseñan con vocación: dar de sí todo al niño, es decir, a la patria" (p. 10).

El ordenamiento del libro, situado al final, aparece de un modo particular. La autora presenta un detalle de lo narrado para que sea apropiado por el maestro y usado ante la aparición de dudas sobre el desarrollo de los temas. Lo suyo es un índice-guía que alude a las páginas que desea referenciar y aclara, por ejemplo, que en la página 11 aparece la "Introducción de la palabra generadora sol, que se enseñará como un todo". Otros ejemplos de este índice se reproducen a continuación: "12- Descomposición de la palabra sol. Sílabas ol y so; letras s-o y l"; "13- Afianzamiento de lo enseñado e introducción de la letra de imprenta. Derivadas: lo y solo"; "14- llustración destinada a fijar la atención del niño, representando una escena: 'la recolección de la sal'”.

Más adelante aparecen: "19- Afianzamiento de lo enseñado e introducción de nuevos derivados"; "20- Recapitulación de lo enseñado y enseñanza de la mayúscula L"; "30- Empleo del acento. Ejercitación. Introducción de la I y de la $S$ mayúsculas"; "90Lectura corriente 'Los deditos' (Verso)" y "106- Lectura corriente 'Un ayudante que nada pide"'. 
Esta publicación utiliza imágenes que acompañan las letras imprentas y cursivas; gran variedad de oraciones; diálogos en los que se discriminan preguntas de respuestas y afirmaciones de enunciados, para enseñar a leer y a escribir a los pequeños de primer grado. Con cuentos breves incluidos en las conversaciones o poemas en los cuales los animales cobran vida y opinan sobre sus experiencias, los niños aprenden también sobre el mundo de la economía doméstica del hogar y los quehaceres familiares.

En una gran pluralidad de temas figuran instrucciones para el armado de un barrilete; oraciones que procuran que los alumnos se apropien de las letras y las sílabas; enumeraciones en las que los autores son los chicos; fábulas con moralejas; composiciones que pueden ser usadas como canciones para aprender, por ejemplo, la cantidad de días que tienen los meses; rimas, odas y transcripciones de cuentos (por ejemplo, uno de autoría de Amado Nervo) para conocer, entre otras cosas, el calendario.

\section{El hogar de todos, de Clara de Toro y Gómez}

Por último, y en calidad de libro de lectura para cuarto grado, contamos con la 23. edición de El hogar de todos (1936), a cargo de la Editorial A. Kapelusz \& Cía, con sede en Buenos Aires. En noviembre de 1923, De Toro y Gómez presenta su obra aprobada por el Consejo Nacional de Educación (expediente 827 K.1930) y los Consejos de las provincias de Buenos Aires y Santa Fe. Esa fecha es la que figura acompañada de la firma de la escritora al inicio, donde detalla los puntos que propone para el programa del grado, junto a las lecturas seleccionadas para tal fin.

El libro se organiza en torno a las temáticas: geografía, historia, ciencias naturales, instrucción moral e instrucción cívica. El índice muestra los títulos que coloca dentro de estos apartados. En la introducción, la autora alega que a causa del éxito de su libro anterior (La escuela y la vida. Libro de lectura para el $3^{\circ}$ grado) decide publicar uno similar, pero para un grado más avanzado, dispuesta a enfrentarse a nuevos desafíos. De Toro y Gómez dice entregar al maestro una serie de lecturas que ayuden al desarrollo de los temas de la enseñanza general que responden al programa oficial presente en todas las escuelas.

La maestra hace uso, además, de cuestionarios que ubica debajo de cada lectura para asegurarse la práctica de ejercicios de reflexión por parte de los estudiantes. Para ello, los dirige a pensar en sus propias vidas y en sus experiencias cotidianas. Lo hace también para lograr que el niño utilice verdaderamente lo que lee, sienta que le es de utilidad y se asocie con sus semejantes gracias a lo posibilitado por la palabra escrita. Coloca asimismo una lista de las palabras más complejas, a modo de diccionario abreviado, y será el maestro el encargado de adecuar a su grupo de alumnos. Este podrá agregar o quitar términos de acuerdo con las necesidades de su clase. La autora también utiliza fragmentos de obras de eruditos argentinos, en el entendido de que con ellos el niño se familiariza con la literatura nacional y sus encantos, al tiempo que obtiene buen estilo y pureza en el lenguaje. 
El libro presenta dos índices: uno general, que enumera la totalidad de los temas (desde el número 1 que es "El hogar de todos y hasta el 79 que se llama "La irresolución") y otro que revela una modalidad más metódica y agrupa lecturas según asuntos. Ellos son: "I. La familia-el hogar"; "II. La patria"; "III. La conducta-defectos y cualidades"; "IV. El trabajo y la escuela"; "V. La naturaleza”.

La obra contiene citas de personalidades como Félix Florián, Marcos Sastre, Belisario Roldán, Nicolás Avellaneda, Esteban Echeverría; y textos de Víctor Hugo, Rafael Obligado, Joaquín Costa, Carlos Guido y Spano, Lucio V. López y Bartolomé Mitre. Incluso hay una aproximación a una biografía de Sarmiento interpretada por Carlos Pellegrini y un tratamiento sobre la historia internacional a cargo de Carlos Octavio Bunge. Hay escritos que no indican autor, por lo que se supone que son de De Toro y Gómez. Casi todos los escritos están firmados por hombres, con excepción de los de la autora y unos atribuidos a Amelia Palma, mujer que habla acerca de las amistades y el deber de la felicidad. Hay, al igual que en los libros de las otras maestras, protagonistas de los relatos que se repiten en las historias, quizás con la intención de dar continuidad a las narraciones e invitar a los estudiantes a elaborar producciones propias en base a las lecturas.

Otros contenidos son descripciones de algunos lugares del país, estudiados detenidamente con sus accidentes geográficos y las características de su población, y preceptos religiosos que aparecen a través de oraciones que, por ejemplo, hablan sobre el valor del trabajo e interpelaciones como "En un valle de lágrimas", provenientes de invocaciones devotas. El libro posee escritos extensos, con arduas descripciones que aportan máximas, parábolas y metáforas que incluyen términos pertenecientes a un vocabulario complejo, muchas veces acompañadas por juegos de palabras que refuerzan el trabajo sobre ortografía.

Por otra parte, el libro presenta imágenes acompañando los textos, entre las que se destacan las "Estampas": fotografías que ocupan toda una carilla del libro y se encuentran reseñadas con el fin de dar a conocer, por ejemplo, animales autóctonos junto a la historia sobre sus hábitats.

Luego de este repaso por el contenido de los cinco libros, se desarrollan en el siguiente apartado unas reflexiones finales que ayudarán a comprender la escritura de estos libros por parte de las maestras. Pensar en estas obras escritas por mujeres vinculadas al magisterio - proceso feminizado promovido por el propio Estado argentino desde las últimas décadas del siglo XIX por razones ideológicas y económicas (Fiorucci, 2016, p. 135) - nos convoca a preguntarnos si la contradicción en el trato a las mujeres -restringidas en sus derechos civiles y políticos, pero responsables de educar al ciudadano- las llevaron a inmiscuirse dentro de las prácticas de enseñanza primero para luego abandonarlas con el fin de ocupar lugares inexplorados por muchas de ellas, como el propio ámbito de la escritura. 


\section{REFLEXIONES SOBRE LOS LIBROS ESCRITOS POR MAESTRAS ARGENTINAS}

A lo largo de este artículo se realizó una aproximación al contenido de cinco libros elaborados por seis maestras. La redacción de uno de ellos en coautoría nos conduce a pensar en duplas de maestras comprometidas con una labor educativa de creación de saberes. Si bien estaban alejadas de la cotidianeidad escolar, se encontraban próximas a las problemáticas que de ella surgían, y que las inquietaban lo suficiente como para que se lanzaran a escribir. En este apartado se presentan algunos acercamientos reflexivos al tema estudiado, a modo de conclusiones primarias.

En primer lugar, se planteó una breve contextualización sobre el período en el que surgieron estos libros de texto a manos de maestras argentinas, que intentaban auxiliar a docentes y alumnos en la tarea cotidiana llevada adelante en los salones de clase de la educación primaria. Aunque esta indagación arrojó ciertas certezas, también dio lugar a nuevas preguntas: ¿quiénes fueron estas mujeres?, ¿dónde estudiaron primero y se desempeñaron en el magisterio luego?, ¿qué experiencias laborales vivenciaron?, ¿qué motivos las impulsaron a escribir sobre educación?, ¿cómo pudieron dar a conocer sus escritos?, ¿qué requisitos, exigencias y requerimientos debieron cumplir para publicar sus obras?, ¿qué sucesos las impulsaron a asumir dichos desafíos? Y, finalmente, ¿cuáles fueron las relaciones que entablaron, y con quiénes, para poder renunciar a la labor docente y desempeñarse dentro de las prácticas de escritura?

Estudiar libros de texto escolares publicados entre 1923 hasta 1936 nos permite cruzar la labor desempeñada en la docencia por estas educadoras que, gracias a dicho trabajo, pudieron emprender la osada tarea de diseñar materiales de estudio. Al notar la gran cantidad de maestras involucradas en la práctica de escribir para sus alumnos, decidimos seleccionar a seis de ellas para reflexionar sobre el modo en que presentaron los materiales de estudio, la forma en que se lucieron como docentes en los textos, las similitudes y diferencias presentes en estas obras.

Los aportes de Roger Chartier (2001, 2005a, 2005b, 2008; Goldman y Arfuch, 1995) permiten comprender los procesos de escritura y lectura en íntima relación con las experiencias prescriptivas, que se vuelven objeto de análisis al poseer una fuerza performativa en su búsqueda por hacer cosas con las palabras. Los escritos pretenden hacer algo en y con otros, fijan líneas de acción para el quehacer escolar presuponiendo que los lectores - aquí docentes y alumnos- actúan en consecuencia. A partir de esta noción, nos preguntamos por el sujeto mujer que diseña y escribe (Perrot, 2008), pensando en maestras que ofician como otros intelectuales, con autonomía, producción crítica y saberes de acción, pero desde los bordes del campo intelectual en su calidad de maestras y de mujeres (Fiorucci, 2013).

Estas maestras escribieron sobre el saber escolar para su progreso, poniendo en escena con sus libros cuáles fueron las prácticas de lectura y escritura que generaron estos dispositivos en el espacio áulico, como así también las concepciones que docentes, escritores de textos escolares y funcionarios asumieron en torno al texto 
escolar (Sardi, 2010, p. 121). Analizando sus prólogos y advertencias, dilucidamos las miradas que estas mujeres educadoras les otorgaban a sus libros, los usos, estilos y propuestas pedagógicas y didácticas que encontraron la posibilidad de hacerse visibles.

La mirada arrojada sobre la temática del presente artículo estaba guiada, como se mencionó, por la historia con mujeres en perspectiva de género, la historia cultural y la historia de la educación. El aula aparece aquí como lugar posible de historiar, tanto en sus aspectos materiales como en sus significados, actores y experiencias (Viñao Frago, 2008). Y así, nos topamos con un grupo de maestras que, preocupadas por las prácticas, escribieron para sus alumnos y quedaron totalmente ocultas detrás de sus producciones.

Con esto pudimos reflexionar sobre el accionar de las mujeres dedicadas a la docencia que trascendieron dicha labor para escribir. Mientras que algunas como Gabriela Mistral, Alfonsina Storni o Herminia Brumana lo hicieron en la prensa o en la literatura, otras (como Olga Cossettini o las autoras estudiadas aquí) lo hicieron centradas en el ámbito de la pedagogía. Las maestras argentinas, interesadas en los modos de aprender de sus alumnos, permanecieron invisibles detrás de sus orientaciones prácticas acerca de los saberes escolares, debiendo dispersarse tras los sucesos intrincados de la dinámica escolar. Con títulos de maestras normales nacionales, como poseedoras del conocimiento y la destreza en las prácticas de lectura y escritura, estas mujeres intervinieron en el ámbito público de las aulas vivenciando las prácticas y escribiendo sobre ellas, pero su autoría quedó escondida detrás de dicho accionar.

Un punto en común entre las maestras estudiadas en este artículo es que ellas afirmaron en sus propios escritos que, luego de años en la docencia (considerada femenina), decidieron exceder el límite de las aulas para reconocerse como escritoras y autoras, asumiendo tareas propias del oficio intelectual y sintiéndose en condiciones de hacerlo por los considerables años de trabajo en las escuelas. Así, intentaron ocupar un sitio hasta el momento dominado por los varones, pero este espacio no logró evidenciarlas: no supimos quiénes fueron ni cuáles fueron sus recorridos personales e intelectuales. Esas peculiaridades se diluyeron bajo la importancia otorgada a los textos escolares en los que las podemos ubicar (el mundo de las prácticas educativas); obras de divulgación y acercamiento a los contenidos que se consideraban fundamentales para formar al niño como futuro ciudadano comprometido con los valores nacionales (Sardi, 2010, p. 77).

En todos los casos nos encontramos con mujeres adheridas al ejercicio de la docencia y, por tal motivo, preocupadas por los avatares que en esa actividad suceden a diario. Con la escritura de sus libros, intentaron proponer soluciones a estos problemas mediante fórmulas, secretos, instrucciones y pautas a modo de prescripciones para sus colegas.

Como se pudo ver, las publicaciones contenían numerosas similitudes por encontrarse en condición de libros registrados bajo la ley de propiedad intelectual $\mathrm{N}$. 응 11.723 y aprobados por el Consejo Nacional de Educación (en conformidad con lo 
establecido por la Ley de Educación Común N. 1420). Sus contenidos coincidían en varios aspectos: todos poseían escritos acompañados por imágenes (muchas de las cuales se encontraban reseñadas en los índices); en algunos las poesías eran escritas por las propias maestras y en otros abundan las de escritores nacionales; era común la presencia de juegos de palabras para aprender las reglas ortográficas y gramaticales.

También hay un vínculo estrecho entre los títulos de los libros y lo que en ellos se lee. Por ejemplo, en una narración hacia el final del libro de Olguín y Zamora Grondona (1936) se lee:

Al depositar en mi biblioteca este amigo de todo un año, esta Lucha querida en la que tantas cosas he aprendido, quédome pensando cómo he empleado estos días de mi existencia. Y mi conciencia, ese juez inexorable, que señala nuestras acciones tal como ellas son, está tranquila (p. 250).

Por otra parte, la historia nacional ocupó un renglón interesante a causa de la citada Ley de Educación Común. Uno de los objetivos de la disciplina en el currículum de las escuelas primarias fue lograr que los alumnos conocieran los acontecimientos más representativos de la historia argentina (Finocchio, 2009; 2010). Esto ser aprecia en los detalles minuciosos que aparecen sobre esta temática en los escritos analizados, muchos de los cuales coinciden en las menciones de, por ejemplo, los muertos por la patria: San Martín, Rivadavia, Belgrano, Sarmiento, Moreno, Alberdi, Ameghino, Pirovano. Estrofas o relatos que provocan la reflexión son frecuentes en esta temática, así como la historia de ciudades, la evocación a las distintas efemérides celebradas durante el año lectivo y descripciones similares sobre el escudo nacional, que aparece en varios de los libros con una explicación equivalente. Lo mismo sucede en relación con los temas de economía doméstica y a la cocina, ambas exaltadas en beneficio de la salud física y moral de las familias (Caldo, 2017, p. 103). Todos estos libros fueron aprobados para ser usados por los maestros en las escuelas y sus autoras aclaran que, sin la ayuda de sus colegas, no hubieran podido editar sus publicaciones.

En definitiva, y por fuera del contenido propio y coincidente de las obras, emerge una conclusión interesante que refleja a estas maestras autoras. El magisterio les facilitó su acercamiento a la escritura a través de libros de texto que podemos pensar como un producto artesanal que las vinculó directamente con su realidad material (Sennett, 2009). Esto tuvo como consecuencia el dejarlas ocultas detrás de sus escritos, como evidencia la dificultad para hallar documentos que hablen sobre sus experiencias personales y que permitan biografiarlas, pensar en quiénes fueron y dimensionar la forma en que sus saberes permanecieron en la práctica. Pero, además, no les posibilitó salirse de los límites de las aulas ni dejar de pensar en lo allí ocurrido. El breve esbozo de estas indagaciones realizado en este artículo funciona a modo de punto de partida para profundizar las investigaciones sobre esta temática. 


\section{REFERENCIAS}

Alloatti, N. (2007). Cuentos y lecciones: textos para los niños decimonónicos en Argentina. Revista oCNOS, 3, 91-101.

Aróstegui, J. (1995). La investigación histórica: teoría y método. Barcelona, España: Crítica.

Caldo, P. (2017). Un cachito de cocinera. Mujeres, libros y recetas de cocina en la Argentina de fines de siglo XIX y principios del XX. Rosario, Argentina: Casagrande.

Caldo, P., Pellegrini, M., y Mosso, A. (2016). Los usos sociales de la historia. La estrategia de Olga Cossettini, Rosario 1935 - 1943. Panta Rei Revista digital de ciencia y didáctica de la Historia, 97110. https://doi.org/10.6018/pantarei/2016/6

Chartier, R. (1999). Cultura escrita, literatura e historia. México D. F., México: Fondo de Cultura Económica.

Chartier, R. (2001). Escribir las prácticas. Foucault, de Certeau, Marin. Buenos Aires, Argentina: Manantial.

Chartier, R. (2005a). Pluma de ganso, libro de letras, ojo viajero. México D. F., México: Universidad Iberoamericana.

Chartier, R. (2005b). El pasado del presente. Escritura de la historia, historia de lo escrito. México D. F., México: Universidad Iberoamericana.

Chartier, R. (2008). ¿Existe una nueva historia cultural?. En S. Gayol, M. Madero (Eds.), Formas de historia cultural (pp. 29-46). Buenos Aires, Argentina: Prometeo Ediciones.

Congreso de la Nación Argentina. (1884). Ley No. 1420. Ley reglamentando la Educación Común. Recuperado de https://www.apdh-argentina.org.ar/sites/default/files/u7/Ley_1420.pdf

De Toro y Gómez, C. (1936). El hogar de todos (23aㅡ ed.) Buenos Aires, Argentina: Kapelusz.

Del Prado, A. (1932). Sol ( 4⿳亠丷a ed.). Buenos Aires, Argentina: Editorial Independencia.

Finocchio, S. (2009). La escuela en la historia argentina. Buenos Aires, Argentina: Edhasa.

Finocchio, S. (2010). Una cartografía de saberes escolares en movimiento para América Latina. Propuesta Educativa, 34, 65-76.

Fiorucci, F. (2013). Presentación. Prismas: revista de historia intelectual, 17(2), 165-168.

Fiorucci, F. (2016). País afeminado, proletariado feminista, mujeres inmorales e incapaces: la feminización del magisterio en disputa (1900-1920). Anuario Historia de la Educación, 17(2), 120-137.

Goldman, N., y Arfuch, L. (1995). Historia y prácticas culturales. Entrevista a Roger Chartier. Historias, 35, 3-17. Recuperado de https://www.estudioshistoricos.inah.gob.mx/revistaHistorias/wpcontent/uploads/historias_35_portada.pdf

lantorno de Nasino, M. (1926). Por nuestro bien. Buenos Aires, Argentina: Talleres Gráficos Cappellano Hermanos.

Kaufmann, C. (Coord.). (2012). Textos escolares, dictaduras y después. Miradas desde Argentina. Alemania, Brasil, España e Italia. Buenos Aires, Argentina: Prometeo. 
Lionetti, L. (2007). La misión política de la escuela pública. Formar al ciudadano de la República (18701916). Buenos Aires, Argentina: Miño y Dávila.

Malvigne de Mercado Vera, E. (1930). Días de sol (3ª ed.). Buenos Aires, Argentina: F. Crespillo.

Olguín, M., y Zamora Grondona, V. (1936). Lucha (10ª ed.). Buenos Aires, Argentina: Ángel Estrada \& cía.

Perrot, M. (2008). Mi historia de las mujeres. Buenos Aires, Argentina: Fondo de Cultura Económica.

Puiggrós, A. (1996). Qué pasó en la educación argentina. Breve historia de la conquista hasta el menemismo. Buenos Aires, Argentina: Kapelusz.

Sardi, V. (2010). El desconcierto de la interpretación. Historia de la lectura en la escuela primaria argentina entre 1900 y 1940. Santa Fe, Argentina: Universidad Nacional del Litoral.

Sennett, R. (2009). El artesano. Barcelona, España: Anagrama.

Solari, M. (1991). Historia de la Educación Argentina (13ae ed.). Buenos Aires, Argentina: Paidós.

Terradas, I. (1992). Eliza Kendal. Reflexiones sobre una anti biografía. Barcelona, España: Universidad Autónoma de Barcelona.

Viñao Frago, A. (2008). La escuela y la escolaridad como objetos históricos. Facetas y problemas de la historia de la educación. História da Educação, 12(25), 9-54.

Yannoulas, S. (1996). Educar. ¿Una profesión de mujeres? La feminización del normalismo y la docencia. 1870-1930. Buenos Aires, Argentina: Kapelusz. 